\title{
The relationship between organizational commitment and nursing care behavior
}

Mohammad Hossein Khalilzadeh Naghneh ${ }^{1}$, Mansoureh Zagheri Tafreshi², Manijeh Naderi ${ }^{3}$, Nehzat Shakeri ${ }^{4}$, Fariba Bolourchifard ${ }^{5}$, Naser Sedghi Goyaghaj ${ }^{6}$

${ }^{1}$ M.Sc. Student of Nursing, School of Nursing \& Midwifery, Shahid Beheshti University of Medical Sciences, Tehran, Iran

${ }^{2}$ Ph.D. in Nursing, Associate Professor, Department of Nursing, School of Nursing \& Midwifery, Shahid Beheshti University of Medical Sciences, Tehran, Iran

${ }^{3}$ M.Sc. in Nursing, Instructor, Department of Nursing Management, School of Nursing \& Midwifery, Shahid Beheshti University of Medical Sciences, Tehran, Iran

${ }^{4}$ Ph.D. in Biostatistics, Assistant Professor, Department of Biostatistics, School of Paramedical Sciences, Shahid Beheshti University of Medical Sciences, Tehran, Iran

${ }^{5}$ Ph.D. in Nursing, Assistant Professor, Department of Medical Surgical Nursing, School of Nursing \& Midwifery, Shahid Beheshti University of Medical Sciences, Tehran, Iran

${ }^{6}$ M.Sc. of Medical Surgical Nursing, Nursing Department, University of Social Welfare and Rehabilitation Sciences, Tehran, Iran

\section{Type of article: Original}

\begin{abstract}
Introduction: Nursing care encompasses physical, emotional, mental and social needs, in order to improve a patient's health and wellbeing. Caring is the central core and the essence of nursing. The important issue of care is access to proper care and increasing patients' satisfaction. Job performance of nurses is affected by many factors including organizational commitment. This study aimed to determine the relationship between organizational commitment and nurses caring behavior.

Methods: In this cross-sectional study, 322 nurses from selected Hospitals of Shahid Beheshti University of Medical Sciences in Tehran were randomly selected and enrolled in the study in 2015. The self-reported data by nurses were collected through demographic characteristics questionnaire, Meyer \& Allen organizational commitment model and Caring Behavior Inventory (CBI). Data were analyzed with SPSS statistical software version 20, using t-test and ANOVA.

Findings: The majority of nurses $(63 \%)$ were female. The mean score and standard deviation of organizational commitment and caring behavior of nurses were $74.12 \pm 9.61$ and $203.1 \pm 22.46$, respectively. The results showed a significantly positive correlation between organizational commitment and caring behavior $(\mathrm{p}=0.001)$.

Conclusion: In this study the caring behavior of nurses with higher organizational commitment were significantly better than the others. Managers and nurse leaders should pay more attention to improve organizational commitment of nurses, in order to improve nurses' performance.
\end{abstract}

Keywords: Nurse, Organizational commitment, Caring behavior

\section{Introduction}

Nursing care with the aim of improving patient's health not only is concerned with the physical needs of a patient, but also encompasses the entire mental, spiritual and social needs of the patient (1). The theoretical foundations of nursing are based on the understanding of care and caring behavior (2). Since the 1980s, nurses in western countries have moved from theory to practice and emphasized nursing care as the heart of care practice (3). As a consequence

\section{Corresponding author:}

Associate Professor Dr. Mansoureh Zagheri Tafreshi, Department of Nursing, School of Nursing \& Midwifery, Shahid Beheshti University of Medical Sciences, Tehran, Iran.

Tel: +98.2188202519, Fax: +98.2188202519, Email: m.z.tafreshi@sbmu.ac.ir

Received: July 31, 2016, Accepted: October 10, 2016, Published: July 2017

iThenticate screening: October 02, 2016, English editing: November 22, 2016, Quality control: March 16, 2017

(C) 2017 The Authors. This is an open access article under the terms of the Creative Commons Attribution-NonCommercialNoDerivs License, which permits use and distribution in any medium, provided the original work is properly cited, the use is non-commercial and no modifications or adaptations are made. 
of conscious care behavior, the quality of care increases the sense of security in patients, and reduces patients' anxiety. (4). Cowin \& Warelow believe that a deep understanding of the concept of care and putting it into action, has an important effect on the quality of services provided by nurses, and more importantly, on understanding nursing practices (5). Care is the core of these practices, and has an important role in determining patients' satisfaction with the experience of hospitalization (6). The results of studies on understanding caring behavior, suggest that there is no similar understanding of care in various other societies (5). Although the concept of care, philosophically speaking, is the mission of many organizations and health institutions, nursing care in the health system still remains as a complex concept that has no precise definition (7). Although it is generally appreciated by nurses that care is the core concept of nursing, the attention to this concept is very low and even declining (8). Two main aspects of care are physical-technical and psycho-social aspects. A study by Christopher \& Hegedus in 2000, showed the psycho-social aspect as the most important aspect of caring behavior, while studies in Iran show that nurses pay more attention to the physical-technical aspect of care in comparison to psycho-social aspect (5). Nurses' job performance as one of the most important professions within the hospital, is affected by several factors, particularly organizational commitment (9). Organizational commitment is an important variable in understanding employee behavior that has potentially serious effects on the performance of the organization, and ignoring it has been harmful for the organization $(10,11)$. Failure to research and study the employees' commitment to the organization, leads to a huge increase in costs due to staff turnover and recruiting new employees, low performance as well as establishment of precise and complicated control mechanisms (12). The result of a study showed that there was significant relationship between organizational commitment and staff turnover, so that increasing organizational commitment leads to reducing turnover. (13). Organizational commitment results in increased effort, motivation, job satisfaction, lower absenteeism from work and increased retention in the organization $(12,14)$. Organizational commitment has been considered by Allen and Meyer as a mental connection between an employee and an organization that causes fewer employees to voluntarily leave the organization. Organizational commitment has three components; normative, continuous and emotional commitment (15). "Emotional commitment" represents the desire and attachment of the individual to the organization, identification with the organization and willingness to participate actively in it. "Continuance commitment" shows the individual subjugation to the organization and the costs of leaving the organization, which is presented in two forms of the absence of suitable job opportunities and loss of experience. "Normative commitment" has been described as a sense of loyalty to the values and goals of the organization (16). Studies show that committed employees are more loyal in their behavior (17). Organizational commitment can bring about a sense of satisfaction, belonging, affiliation and attachment of employees to the organization, more favorable job performance, and financial success, and can increase the effectiveness and efficiency of the organization (13). A researcher, during his study and work as a nurse, witnessed differences in nurses' caring behavior from different aspects such as communication and care given to patients, and employment experience and skills; and these differences raised the question in his mind, whether those who have a higher organizational commitment would have a better caring behavior to patients or not. For this purpose, a literature review was performed and a study which measures the correlation between these two variables was not found in the country. Therefore, the aim of this study was to investigate nurses' organizational commitment and their caring behavior in selected hospitals in Tehran.

\section{Material and Methods}

This 2015 cross-sectional study was performed on nurses working in selected teaching hospitals of Shahid Beheshti University of Medical Sciences in Tehran including Shohada Tajrish, Loghman Hakim, Imam Hossein and Ayatollah Taleghani hospital. The sample size for this study was 350 of which 322 questionnaires were returned for a rate of $92 \%$. Inclusion criteria for nurses working in surgical and internal wards were as follows: history of at least one year work experience, at least a bachelor's degree in nursing, working in the sector as a nurse during the conduction of research (not including supervisors or matron), have full consent to participate in this research. In this study, three instruments including nurses' demographic information questionnaire (such as age, gender, etc.), Allen \& Meyer organizational commitment questionnaire consisting of 24 questions and Caring Behavior Inventory were used, to collect data. In the Organizational Commitment Questionnaire, eight items were used to measure each of the three components of emotional, continuance, and normative commitment. The participants showed their agreement with each of the items, using the Likert scale ranging from $1=$ Strongly Disagree to $5=$ Strongly Agree. The minimum and maximum score was between 24 and 120 for a total organizational commitment and organizational commitment scores for each aspect were between 8 and 40. Caring Behavior Inventory which was designed 1981 by Wolf, based on Watson Care Theory in 1986 was used for the first time in this study, for measuring nurses caring behavior. The list had 42 items and five subscales including respect to others (12 items), assurance of human presence (12 items), communication and positive attitude ( 9 items), knowledge and professional skills (5 items) and 
attention to other's experiences (4 items). Items were based on the 6-point Likert scale, ranging from 1=never to $6=$ always. To measure the average of each subscale, the scores of each subscale were summed and the total score was divided by the number of items. To calculate the average (index of caring behavior), scores of all items were summed and then divided by 42 . In addition, the minimum and maximum scores of caring behavior index were 42 and 252, respectively. The score of each subscale was between score 1 to 6 . This means that the scores achieved in each of the subscales are divided by the number of items for each subscale. In this study, qualitative content validity method was used in order to determine the validity of organizational commitment and caring behavior. In this method, factors such as difficulty levels, clarity, simplicity and relevance were assessed by 15 members of the Faculty of Nursing and Midwifery at Shahid Beheshti University of Medical Sciences. Additionally, face validity of instruments was evaluated by surveying ten nurses who had the inclusion criteria and were not enrolled in the study (were not among the study population). Moreover, internal consistency was used, to determine the reliability of organizational commitment, and caring behavior questionnaires, and Cronbach's alpha was calculated, so that twenty nurses were excluded from the subject group and were considered as the control group. The questionnaires were then completed by the group and the amount of Cronbach's alpha was calculated. The amount of Cronbach's alpha for organizational commitment and Caring Behavior Inventory was 0.81 and 0.97, respectively. Quota and convenient sampling (based on the number of nurses in each hospital) method was used to select the eligible subjects who had the inclusion criteria. The permission of the management of each hospital was obtained for sampling. Then the objective of the research was explained to the nurses and after obtaining their oral and written informed consents, the organizational commitment and caring behavior questionnaires were given to the nurses in each shift to be completed and returned by the end of the shift or the following shift. The research units were free to fill the questionnaires and the information was recorded anonymously and kept confidential. Data were analyzed by IBM $\odot$ SPSS $\odot$ Statistics version 20 (IBM $\odot$ Corp., Armonk, NY, USA) using t-test and ANOVA to achieve the objectives of the study.

\section{Results}

A total number of 322 people were enrolled in the study. The majority of nurses $(63 \%)$ were women. The minimum age was 21 and maximum age was 56, with an average of 32.04 7.84. Most nurses (126 cases, 39.1\%) were contract employees, 172 nurses $(53.4 \%)$ worked rotating shift, and 224 nurses $(69.6 \%)$ had less than 5 years of work experience in their current hospital. Most nurses were working in an internal ward (65 people, 20.2\%) and surgical ward for males (58 people, 18\%). A total of 227 people (70.5\%) were only working in the hospitals where sampling was performed. Minimum and maximum score of organizational commitment was 38 and 103 respectively, with the average score of $74.12 \pm 9.61$. Post hoc test results showed a significant difference in the mean score of commitment between the three aspects of organizational commitment $(\mathrm{p}<0.005)$ and based on that, "continuance commitment" with an average of 25.70 was greatest and "normative commitment" with an average of 23.67, was the lowest subscale of organizational commitment. The minimum score of nurses' caring behavior was 96 and the highest score was 24 with an average score of 203.1 \pm 22.46 . Post hoc test results showed that there is no statistically significant relationship between the mean scores of subscales of respect to others and assurance of human presence; assurance of human presence and attention to others experiences; knowledge and professional skills and attention to others' experiences. The lowest score was related to the subscale of communication and positive attitude (4.72). The data show that there was a significant positive correlation between emotional and normative commitment with caring behavior ( $\mathrm{p}=0.005$ ), but there was no statistically significant correlation between continuous commitment and caring behavior $(\mathrm{p}=0.368)$. In total, there was a significant positive correlation between organizational commitment and caring behavior $(\mathrm{p}=0.001)$. In addition, regression analysis showed that marital status and organizational commitment remain as predictor variables of caring behavior in the model $(\mathrm{p}<0.005)$.

\section{Discussion}

This study aimed to determine the correlation between organizational commitment and caring behavior of nurses working in Shohada Tajrish, Loghman Hakim, Imam Hossein and Ayatollah Taleghani Hospitals, in the city of Tehran. Based on the obtained results, the mean score of organizational commitment of nurses was 74.12 (ranging from 38 to 103), which shows the commitment of nurses in the hospitals was in a moderate level. Also, "continuance commitment" with an average score of 25.70 and "normative commitment" with an average score of 23.67, accordingly had the greatest and lowest score among subscales of organizational commitment. According to the study by Seyyed Gheibi et al. which was carried out on nurses working in Shiraz University affiliated hospitals, the score of continuance and normative commitment were 4.05 and 3.14 respectively. Considering the mean score of organizational commitment (52.57\%), the nurses' commitment was moderate, which was consistent with our results (11). Delgoshaei et al. showed that the mean score of organizational commitment of employees and managers of 
teaching hospitals of Hamadan University of Medical Sciences was 78.48, and that emotional (27.18) and normative commitment (25.31) had the maximum and minimum score among subscales of organizational commitment. In this research, the moderate level of commitment was in line with the present study (18). Rahmanzadeh et al. (10) reported an average level of organizational commitment (80.9\%) in nurses working in hospitals affiliated to Tehran University of Medical Sciences. In line with our study, normative commitment had the lowest score (38.9\%) and continuous commitment had the highest score (42.4\%). In addition, Mahmoudi-Rad et al. (19) reported a mean score of 95.01 for organizational commitment of nurses working in Valiasr hospital in Birjand while the lowest score was related to emotional commitment (30.46) and the highest score was related to continuous commitment (32.88). Total score of organizational commitment was in the average rating level that is consistent with present study. Furthermore, the results of other studies by Nabizadeh et al. (20), Radabadi et al. (21), Golden and Veiga (22), and Yaghoubi et al. (23) were in line with our research. However, Lavasani et al. (24) showed that the nurses' commitment in Tehran was higher than average and in contrast; Hadizadeh- Talasaz et al. (25) reported a low level of organizational commitment among midwives. The discrepancy between the reported results can be due to the difference in environments, study population, time of the study, sample size and instruments. The average score of nurses caring behavior was 203.1 (from a minimum of 42 to a maximum of 252), which also shows that the nurses caring behavior is very favorable. This finding is in line with the results of studies by Joulaei et al. (26) and Hajinejad et al. (27). It should be noted that in this study, the nurses' perspective was investigated whereas in other studies, patients' perspective has been examined. Sayed Al-shohadaei et al. indicated a low level of nurses caring behavior (28) which was in contrast with the results of this study. Working in different wards (internal, surgical, cancer etc.) could be a good reason to justify the differences. Professional knowledge and skills and attention to others experiences had the highest score among subscales. These findings are consistent with the results of studies by Sayed Al-shohadaei et al. (28), Haji-Nejad et al. (27), Wolf et al. (29) and Roper et al. (30). Given the importance of the knowledge and skills in providing quality care which has been proven by several studies, it can be said that proper educational planning, appropriate and effective teaching practices and strengthening the knowledge and skills of nurses is very important. According to the results, there was a significant positive correlation between organizational commitment and caring behavior of nurses. This means that with increased commitment, nurses caring behavior has improved. This has been verified by several studies. For instance, Dehghanizadeh concluded that organizational commitment is a strong predictor for nurses' job performance (9). In addition, Kim et al. noted that nurses' job satisfaction is one of the most important factors affecting organizational commitment, and he believes that higher commitment leads to a lower turnover of nurses (31). Anis et al. regarded the organizational commitment as an effective factor in preventing nurses' turnover (32). Additionally, Gutierrez et al., and Al-Aameri believe that organizational commitment has positive and direct association with the level of nurses' job satisfaction and faculty members of nursing schools $(33,34)$. Alipour et al. and Al-Hawajreh in their studies, indicated that attention and enhancing organizational commitment is a convenient way to reduce occupational stress among nurses $(35,36)$. In a study conducted by Seyedghibi et al., it was found that organizational commitment can be a predictor of nurses' moral sensitivity and can increase it (11). In a study by Ahmad et al., conducted on 110 Bankers in ten banks of Pakistan, it had been shown that increasing organizational commitment can improve the employees' performance (37). This has also been indicated by Tolentino on university staff in Malaysia (38). Furthermore, Fu et al. showed a direct impact of organizational commitment on employees' performance in an insurance company in China (39). According to various studies on nurses in different hospital wards, communities and environments and in different countries, the positive effects of organizational commitment and positive relationship between this issue and caring behavior, performance, job satisfaction and reducing employees' turnover can be inferred.

\section{Conclusions}

In summary, the findings showed a significant positive correlation between organizational commitment and caring behavior, so that by increasing organizational commitment, nurses caring behavior improves. Practical significance of this finding is that nurses and healthcare providers can pay more attention to the organizational commitment among nurses, in order to provide the necessary conditions and to take further steps for improving caring behavior among nurses. It is recommended that regular conferences and meetings should be held, with the participation of nurses in various hospitals around the country, in order to provide introductory and training programs for nurses to increase organizational commitment. Performing a complementary research on nurses for educating organizational commitment with interventional methodology could open many interesting avenues for future research on this topic.

\section{Acknowledgments:}

This article is taken from a Master's Degree thesis in nursing at Shahid Beheshti University of Medical Sciences, number SBMU2.REC.1394.155, approved in 11/03/2015 which was conducted in four teaching hospitals in Tehran. 
Hereby, we thank all the respected staffs in post graduate department of the university, Deans and nursing management departments of hospitals for their sincere cooperation as this research would not be possible without their help and support.

\section{Conflict of Interest:}

There is no conflict of interest to be declared.

Authors' contributions:

All authors contributed to this project and article equally. All authors read and approved the final manuscript.

\section{References:}

1) Negarandeh R, Mohammadi S, Zabolypour S, Arazi Ghojegh T. Relationship between quality of senior nursing students' caring behaviors and patients' satisfaction. Journal of hayat. 2012; 18(3): 10-21.

2) Salimi S, Azimpour A, Fesharaki M, Mohammadzadeh S. Nurses' Perception of Importance of Caring Behaviors and Its Determinant factors. Journal of Urmia Nursing \& Midwifery Faculty. 2012; $10(1): 1$.

3) Baljani E, Azimi N, Hosseinloo A. A survey on nurses' perception of the importance of caring behaviors and factors affecting its provision. Evidence based care. 2012; 2(1): 13-21.

4) Liu SS, Franz D, Allen M, Chang EC, Janowiak D, Mayne P, et al. ED services: the impact of caring behaviors on patient loyalty. J Emerg Nurs. 2010; 36(5): 404-14. doi: 10.1016/j.jen.2009.05.001. PMID: 20837208.

5) Asadi SE, Shams Najafabadi R. Nurses' perception of caring behaviors in intensive care units in hospitals of Lorestan University of Medical Sciences, Iran. 2014; 3(3): 170-5.

6) Tang WM, Soong CY, Lim WC. Patient satisfaction with nursing care: a descriptive study using interaction model of client health behavior. International Journal of Nursing Science. 2013; 3(2): 51-6. doi: 10.5923/j.nursing.20130302.04.

7) Zareh Hoshyari Khah H, Moradbeygi K, Shayesteh far M, Elhami S, Cheraghian B, Hatefi moadab N. Impact of a Caring Behavior Educational Program Based on Human Care Theory on Nursing Students' Perception of the Care. Iranian Journal of Medical Education. 2015; 14(10): 836-46.

8) Nikfarid L, Hasani P. Assessment of nursing students' of Azad Islamic university of Saveh' percpective about amount of important caring behavours based on caring model of Watson. 2014; 9(1): 8-16.

9) Hamid N, Dehghanizadeh Z. The relationship between spirituality, organizational commitment and general health with job performance of clinical nurses. Quarterly Journal of nursing management. 2012; 1(2): $20-8$.

10) Rahmanzade E, Parsa Yekta Z, Farahani M, Yekani Nejad S. Nurses' organizational commitment in hospitals affiliated to Tehran University of Medical Sciences. Iran Journal of Nursing. 2014; 26(86): 29-38.

11) Seyedghibi FA, Borhani F. The Relationship between Organizational Commitment and Moral sensitivity of Nurses in hospitals affiliated to Shiraz University of Medical Sciences. International Journal of Management and Humanity Sciences. 2014; 3(8): 2852-62.

12) Shirzad KB, Shamani S, Noroozi M, Shamani S. Comparative Study Of Organizational Commitment And Its Outcomes In Private And State Hospitals Of Semnan Province. Journal Of Healthcare Management. 2012; 4(1-2): 33-42.

13) Bagheri MTR. The effect of organizational commitment on organizational performance. NAJA human resources journal. 2010; 7(30): 73-96.

14) Nägele C, Neuenschwander MP. Adjustment processes and fit perceptions as predictors of organizational commitment and occupational commitment of young workers. Journal of Vocational Behavior. 2014; 85(3): 385-93. doi: 10.1016/j.jvb.2014.08.011.

15) Veličković VM, Višnjić A, Jović S, Radulović O, Šargić Č, Mihajlović J, et al. Organizational commitment and job satisfaction among nurses in Serbia: A factor analysis. Nurs outlook. 2014; 62(6): 415-27. doi: 10.1016/j.outlook.2014.05.003. PMID: 25062809.

16) Mahdavi M, Arab M, Mahmoudi M, Fayazbakhsh A, Akbari F. Organizational Commitment and Intention to Leave among Hospitals' Employees in Tehran Hospitals. Journal of Hospital. 2014; 12(4): 19-29.

17) Zeinabadi H. Job satisfaction and organizational commitment as antecedents of organizational citizenship behavior (OCB) of teachers. Procedia-Social and Behavioral Sciences. 2010; 5: 998-1003. doi: 10.1016/j.sbspro.2010.07.225.

18) Delgoshaei B, Tofighi Sh, Kermani B. The relationship between organizational climate and organizational commitment in teaching hospitals of Hamedan University of medical sciences. Horizon Med Sci. 2009; 14(4): $60-8$. 
19) Mahmoudi Rad Gh, Naeim Hassani S. Relationship between organizational commitment and burnout of nurses working in Valiasr Hospital of Birjand in 2011. Mod Care J. 2014; 10(4): 264-71.

20) Nabizadeh Gharghozar Z, Atashzadeh Shoorideh F, Khazaei N, Alavi-Majd H. Assessing organizational commitment in clinical nurses. Quarterly Journal of Nursing Management. 2013; 2(2): 41-8.

21) Raadabadi M, Mojbafan A, Rajabi VH, Dargahi H. The Relationship of Organizational Commitment and Political Behavior Tendency among the Employees of Tehran University of Medical Sciences. Asian Social Science. 2015; 11(21): 62-70.

22) Golden TD, Veiga JF. The impact of superior-subordinate relationships on the commitment, job satisfaction, and performance of virtual workers. The Leadership Quarterly. 2008; 19(1): 77-88. doi: 10.1016/j.leaqua.2007.12.009.

23) Yaghoubi M, Karimi S, Javadi M, Hassanzadeh A. A survey on relationship between job stress and three dimensions of organization commitment among nursing managers. Scientific Journal of Hamadan Nursing \& Midwifery Faculty. 2010; 18(1): 5-15.

24) Lavasani M, Keyvanzade M, Arjmand N. Spirituality, job stress, organizational commitment, and job satisfaction among nurses in Tehran. J Contemporary Psychology. 2008; 3(2): 61-73.

25) Hadizadeh Z, Norani S, Shakeri M. Evaluation of the relationship between the quality of work life and organizational commitment among midwives working in health-medical centers and maternity of teaching hospitals of Mashhad University of Medical Sciences from 2013-2014. Iran J Obstet Gynecol Infertil. 2014; 17(129): 1-9.

26) Rasti F, Joolaee S, Ghiyasvandian SH, Haghan H. Patients' perceptions of caring behaviors in oncology settings. 2014; 9(1): 59-67.

27) Hajinezhad MS, Rafii F, Jafarjalal E, Haghani H. Relationship between nurse caring behaviors from patients' perspectives \& their satisfaction. Iran Journal of Nursing. 2007; 20(49): 73-83.

28) Seyedoshohadaee M, Mohammadi H, Seyedfatemi N, Mehran A. Relationship between the circadian types and nurses' caring behaviours. Koomesh. 2015; 16(3): 389-96.

29) Wolf ZR, Miller PA, Devine M. Relationship between nurse caring and patient satisfaction in patients undergoing invasive cardiac procedures. Med surg Nurs. 2003; 12(6): 391-6. PMID: 14725151.

30) Raper J, Davis BA, Scott L. Patient satisfaction with emergency department triage nursing care: a multicenter study. J Nurs Care Qual. 1999; 13(6): 11-24. doi: 10.1097/00001786-199908000-00003. PMID: 10476621.

31) Kim M, Kim EJ, Choi S. A Study of Relationship between Nursing Performance, Job Satisfaction, and Organizational Commitment. Advanced Science and Technology Letters. 2016; 128: 94-7.

32) Anis A, Ijaz R, Kashif R, Humayoun AA. Impact of organizational commitment on job satisfaction and employee retention in pharmaceutical industry. African Journal of Business Management. 2011; 5(17): 7316-24. doi: 10.5897/AJBM10.1296.

33) Gutierrez AP, Candela LL, Carver L. The structural relationships between organizational commitment, global job satisfaction, developmental experiences, work values, organizational support, and person organization fit among nursing faculty. J Adv Nurs. 2012; 68(7): 1601-14. doi: 10.1111/j.13652648.2012.05990.x. PMID: 22417004.

34) Al-Aameri AS. Job satisfaction and organizational commitment for nurses. Saudi Med J. 2000; $21(6)$ : 531 5. PMID: 11500699.

35) Al-Hawajreh KM. Exploring the Relationship between Occupational Stress and Organizational Commitment among Nurses in Selected Jordanian Hospitals. Dirasat: Administrative Sciences. 2013; 40(1): 127-43. doi: 10.12816/0000638.

36) Alipour F, Kamaee Monfared M. Examining the Relationship between Job Stress and Organizational Commitment among Nurses of Hospitals. Journal of Patient Safety \& Quality Improvement. 2015; 3(4): 277-80. doi: 10.22038/psj.2015.5250.

37) Ahmad N, Iqbal N, Javed K, Hamad N. Impact of organizational commitment and employee performance on the employee satisfaction. International Journal of Learning, Teaching and Educational Research. 2014; 1(1): 84-92.

38) Tolentino RC. Organizational commitment and job performance of the academic and administrative personnel. International Journal of Information Technology and Business Management. 2013; 15(1): 51-9.

39) Fu W, Deshpande SP. The impact of caring climate, job satisfaction, and organizational commitment on job performance of employees in a China's insurance company. Journal of Business Ethics. 2014; 124(2): 33949. doi: 10.1007/s10551-013-1876-y. 